\title{
Low Iodine Diet for Postoperative Patients with Thyroid Cancer in Vietnam
}

\author{
Nguyen Thu Ha ${ }^{1 *}$, Nguyen Phuc Binh ${ }^{2}$, Dao Thi Hao ${ }^{1}$, Nguyen Dinh Phu ${ }^{1}$ and Tran Hong Nghi ${ }^{3}$ \\ ${ }^{1}$ Department of Nutrition, Vietnam \\ ${ }^{2}$ Institute of Gastroenterology and Hepatology, Vietnam \\ ${ }^{3}$ Department of Nephrology, Vietnam
}

*Corresponding author: Nguyen Thu Ha, Department of Nutrition, 108 Military Central Hospital, Tran Hung Dao Str, Hai Ba

Trung Dist., Hanoi, Vietnam

ARTICLE INFO

Received: 慧 April 02, 2019

Published: April 15, 2019

Citation: Nguyen T H, Nguyen Phuc B, Dao Thi H, Nguyen Dinh P, Tran Hong N. Low Iodine Diet for Postoperative Patients with Thyroid Cancer in Vietnam. Biomed J Sci \& Tech Res 17(1)-2019. BJSTR. MS.ID.002939.

Keywords: Low Iodine Diet; Thyroid Cancer; Vietnam; Nutrition

Abbreviations: DTC: Differentiated Thyroid Cancer; LID: Low Iodine Diet

\begin{abstract}
Low iodine diet and radioactive iodine therapy are required for differentiated thyroid cancer (DTC) patients after thyroidectomy. Vietnam has inadequate data on the amounts of iodine in food. This study aims to provide the recommendation of the amount of iodine in low iodine diet and provide general instructions of low-iodine diet (LID) for Vietnamese. Result: Daily iodine intake of $50 \mu \mathrm{g}$ was recommended for low iodine diet. A two-week low iodine diet was recommended for DTC. The general instructions of restricted iodine diet:

a. Restricted all type of seaweed and seafood.

b. The freshwater food is acceptable.

c. The maximum amount of consumption of meat is $300 \mathrm{~g}$ per day

d. The maximum amount of consumption of grains (rice) is $300 \mathrm{~g}$ per day

e. The maximum amount of consumption of fruits and vegetables is $400 \mathrm{~g}$ per day.
\end{abstract}

Conclusion: Two weeks of $50 \mu$ g daily iodine intake was favored for low iodine diet. Development of Vietnamese databases on Iodine in foods is important to standardize the guideline of low-iodine dietary for Vietnamese.

\section{Introduction}

Thyroid cancer is the most common malignancy of the endocrine system $[1,2]$. It is accounted for $5 \%$ of all cancers diagnosed each year in female and the number is expected to rise [2,3]. The postoperative administration of I-131, also called 'ablation' is one of the benefits required therapy for differentiated thyroid cancer (DTC) patients [4]. The main objectives of ablation are to destroy remaining healthy thyroid cells, to treat remaining cancer tissue, and to recognize and prevent recurrences on patients who have undergone a total thyroidectomy [2,4-6]. The combination of RAI ablation and thyroid hormone has an effective treatment for patients and may reduce long-term cancer recurrence, decrease the prevalence of mortality, and contribute significantly to patients' life expectancy [5]. Thyroid tissue is the place where stored both iodine and radioiodine with the Sodium-Iodide Symporter [6]. However, the DTC tissue has a symptom of Sodium-Iodide Symporter deficiency, hence the rate of I-131 absorption at the DTC is lower than the healthy thyroid $[7,8]$. For this reason, a low-iodine diet for one or two weeks is required before RAI therapy to increase its efficacy in DTC patients after total thyroidectomy. Most guidelines recommend limiting dietary iodine intake to $50 \mu \mathrm{g}$ daily for one to two weeks.

There are several types of research showed that LID could be a source of anxiety because the patients feel they are restricted in eating, the variety of food is limited, and they are confused about how much of food could be eaten. The review on Development of the database on iodine in foods and dietary supplements in 2018 showed that currently, iodine content data were available in the national food composition database of several countries. Vietnam is 
one of the nations, which the national databases have not contained iodine value [9]. In this review, we showed a summary of researches related to the regulars in low iodine diet as well as providing a list of low iodine food and quantity of each food which is familiar and suitable for Vietnamese.

\section{Materials and Methods}

We searched the keywords in English 'low iodine diet', 'radioactive iodine' and 'thyroid cancer' on Medical Science and PubMed website on $27^{\text {th }}$ July 2018. There were 20 papers that were published from 2010. However, because of the requirement in the number of references from the Journal, we selected 13 nearest papers (2011-2018). Two papers were excluded because they were not published in English (Japanese, Korean). Two guidelines from United State and United Kingdom Thyroid association were included. An article from 2005 [8] and the Tables of Food Composition in Japan (2015) [9] were included as references for the iodine content of food groups. A research in Vietnamese were included to show the evidence of using I-131 in post-surgical differentiated thyroid cancer patients in Vietnam [10].

\section{Discussion}

Based on a review of the Nutrition situation in Vietnam from 2009 to 2010, the coverage of households used iodized salt with the iodine level equal to or larger than 15ppm in Vietnam was less than $70 \%$ [11]. Currently, Vietnam is one of 19 countries in the world is in an alarm of iodine deficiency status. American Thyroid Association recommends using I-131 for DTC treatment when urine iodine level is less than $15 \mu \mathrm{g} / \mathrm{dl}$ treatment $[10,12,13]$. According to a 2013 study in Vietnam, the average urine iodine level of DTC patients was $12.7 \pm 8.3 \mu \mathrm{g} / \mathrm{dl}$. Therefore, patients are required to implement lowiodine diet (LID) to meet the treatment standard. Results from that study also showed significant decrease in urine iodine level after 2 weeks of LID $(6.1 \pm 3.96 \mu \mathrm{g} / \mathrm{dl})$ [10]. Iodine is a key mineral which

Table 1: The dietary guideline for a low-iodine diet per day $[13,16,18,19]$.

\begin{tabular}{|c|c|c|c|}
\hline Type of food & Number of servings & Quantity per serving & The maximum amount \\
\hline Grains & $2-3$ & A cup of cooked rice & $300 \mathrm{~g}$ \\
\hline Meat and Meat Substitutes & $5-6$ & $45 \mathrm{~g}$ & $300 \mathrm{~g}$ \\
\hline Milk and dairy products & 0 & $10 \mathrm{~g}=1$ tablespoon $5 \mathrm{~g}=1$ teaspoon & $25 \mathrm{ml}$ fresh milk $5 \mathrm{~g}$ butter \\
\hline Fat & $4-6$ & 1 tablespoon of oil & $50 \mathrm{ml}$ \\
\hline Dessert and Sweets & 2 & 2 tablespoons & $20 \mathrm{~g}$ \\
\hline Fruits and Vegetables & No restrictions & & $400 \mathrm{~g}$ \\
\hline Miscellaneous & No restrictions & & \\
\hline Beverages & No restrictions & & Follow the doctor's instructions \\
\hline
\end{tabular}

Table 2: Iodine content of food groups.

\begin{tabular}{|c|c|c|c|}
\hline & \multirow{2}{*}{ Food group } & \multicolumn{2}{|c|}{ Iodine $(\mu \mathrm{g} / 100 \mathrm{~g})$} \\
\hline & & European (Dried weight) [8] & Japanese (Fresh weight) [9] \\
\hline \multirow{4}{*}{ Cereals } & Rice & 3.33 & 3.0 \\
\hline & Wheat & 3.5 & 0 \\
\hline & Corn & 4.7 & 0 \\
\hline & Potatoes/sweet potatoes/taro & 1.6 & 0.9 \\
\hline
\end{tabular}

is essential in producing thyroid hormones. It is also common in body levels of iodine will be low, and the thyroid gland will send signals to get more iodine. When the patients take a dose of I-131, the thyroid tissue will absorb the radiation iodine more effectively. This will help making the treatment to work better and the test for radiation will be more accurate. The first reference in the literature advising the implementation of a LID prior to I-131 therapy was in 1975. The list of iodine content in food groups was published in 2005. The articles related to the low-iodine diet recommended a variety of food groups depend on the study time and areas.

However, all of them suggested restriction of all kinds of seafood, milk and dairy products, instant food or commercial products (dressing, packaged rice...) [5,14-17]. In this article, most of the guidelines on low iodine diet were updated by Korean researches from 2012 to 2016 [14,15] and the newest guideline from United Kingdom (2018) [18]. The American Thyroid Association and

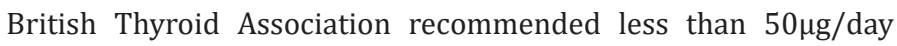
of dietary iodine in 1 to 2 weeks. These associations also provide the number of serving size in their guidelines of LID [5,19]. The concentration levels of iodine in dry matter of food are summarized in Table 1. These data were subtracted from European studies. Table 2 summaries the guideline of low iodine diet with the number of servings per day with the list of food familiar to Vietnamese. A lowiodine diet 1 or 2 weeks before getting doses of radioactive iodine is recommended in most of the studies and guidelines [5,14-16,20]. There was a little to no effect from longer or shorter dietary length of LID. Timing is an important factor because the iodine contents can be changed by areas and individual eating habits $[5,15,20]$. Moreover, it was affected by patient's implementation of the lowiodine diet [15]. Low iodine diet for one week can be enough for adequate preparation of RAI if the DTC patients were given intense education and improved accessibility to medical staffs or dietitians $[5,7,15]$. many types of food. By cutting down on iodine in your diet, the 


\begin{tabular}{|c|c|c|c|}
\hline \multirow{8}{*}{ Meat and Meat Substitutes } & Red meat & 5.9 & 2.0 \\
\hline & Poultry & 6.6 & 5.0 \\
\hline & Egg & 162.5 & 15.0 \\
\hline & Egg, yolk & 141.3 & 39.0 \\
\hline & Egg, white & 21.9 & 5.0 \\
\hline & Fish, marine & 211.2 & 160.0 \\
\hline & Fish, freshwater & 37.5 & 17.0 \\
\hline & Processed meat & 33.5 & 45.0 \\
\hline \multirow{3}{*}{ Milk and dairy products } & Milk & 69.0 & 16.0 \\
\hline & Yogurt & 67.0 & 17.0 \\
\hline & Cheese & 47.3 & 20.0 \\
\hline Fruits & Fresh fruits & 1.8 & 5.0 \\
\hline \multirow{3}{*}{ Vegetables } & Fresh vegetables & 4.7 & 2.0 \\
\hline & Lettuce, parsley, turnip & 23.6 & 7.0 \\
\hline & Fresh mushrooms & 21.1 & \\
\hline Fat & Nuts & 1.3 & \\
\hline \multirow{6}{*}{ Others } & Biscuits & & 4.0 \\
\hline & Cake (+cream) & & 17.0 \\
\hline & Chocolate & & 20.0 \\
\hline & Tea & & 5.0 \\
\hline & Instant Coffee & & 8.0 \\
\hline & Crew Coffee & & 2.0 \\
\hline
\end{tabular}

Hyponatremia was the main side effect that was reported to be in association with a low iodine diet and radioactive iodine therapy. The incidence of severe hyponatremia on LID was low in current studies. Several case reports showed that high-risk factors of hyponatremia were age greater than 65 years, elderly females, and patients use thiazide diuretics $[3,16]$. The restricted regular intake of LID may cause stress, anxiety for patients and taking more time of health staffs in the implementation period $[15,19]$. The patients often reduce their dietary salt intake along the LID period which could lead to complications. For these reasons, the patients should be guided carefully with a short, accurate and concise instruction of low-iodine dietary intake, as well as adequate salt intake during LID [21].

Table 3: Low-Iodine Diet menu for Vietnamese.

\section{Conclusion}

The low-iodine diet was recommended that the dietary iodine intake was lower than $50 \mu \mathrm{g}$ per day. The optimum time of a LID was one to two weeks. The general instructions of restricted iodine diet:

a. Restricted all type of seaweed and seafood.

b. The freshwater food is acceptable.

c. The maximum amount of consumption of meat (beef, pork, chicken) and freshwater food is $300 \mathrm{~g}$ per day;

d. The maximum amount of consumption of grains (rice) is 300 g per day

\begin{tabular}{|c|c|c|c|c|}
\hline & Dishes & Food & & \\
\hline \multirow{3}{*}{ Breakfast } & \multirow{2}{*}{ Noodle with beef } & Noodle (Pho) & A cup & $120 \mathrm{~g}$ \\
\hline & & Beef & 1 serving size & $45 \mathrm{~g}$ \\
\hline & Green tea/ crew coffee & (optional) & a cup & \\
\hline \multirow{4}{*}{ Lunch } & Steam rice & Rice & a cup & $100 \mathrm{~g}$ \\
\hline & Toast & Pork/Chicken & 2 serving size & $90 \mathrm{~g}$ \\
\hline & Fried vegetable & Vegetable (seasoning) & a cup & $100 \mathrm{~g}$ \\
\hline & Vegetable soup & Cabbage & $1 / 2$ cup & $50 \mathrm{~g}$ \\
\hline \multirow{5}{*}{ Dinner } & Steam rice & Rice & a cup & $100 \mathrm{~g}$ \\
\hline & Stew fish & Freshwater fish & 2 serving size & $130 \mathrm{~g}$ \\
\hline & \multirow{3}{*}{ Soup } & Pork ribs & 1 serving size & $45 \mathrm{~g}$ \\
\hline & & Vegetable (seasoning) & a cup & $100 \mathrm{~g}$ \\
\hline & & Taro & $1 / 2$ cup & $50 \mathrm{~g}$ \\
\hline
\end{tabular}




\begin{tabular}{|c|c|c|c|}
\hline \multirow{4}{*}{ Sub-meal } & Steam sweet potatoes/ corn/ Cassava & 1 serving size \\
\cline { 2 - 4 } & Fruits (seasoning) such as Banana/ Dragon fruit/ Guava/ Orange & 1 serving size \\
\cline { 2 - 4 } & Rice-cake (no salt) & 3 medium packs & $45 \mathrm{~g}$ \\
\hline
\end{tabular}

*The nutritional value was calculated based on Vietnamese Food Composition Table [21]: Energy (1700kcal); Protein (68g); Fat (48g); Carbohydrate (250g); Fiber (14.8);

** Estimated Iodine intake was calculated based on Table 2: $47.9 \mu \mathrm{g}$.

e. The maximum amount of consumption of fruits and vegetables is $400 \mathrm{~g}$ per day. A sample of low-iodine diet menu for Vietnamese was showed on Table 3.

The LID instructions in this paper were referred from the food composition databases that include iodine from the other countries. Development of databases on Iodine in foods is important to characterize main sources of dietary iodine, and databases on the iodine content of major dietary contributors provide a key information resource. Based on the national databases, we can standardize the guideline of low-iodine dietary for Vietnamese.

\section{References}

1. Ling Zhi C, Xiao Dong P, Jian Ping X, Fan Hui Y, Hu Ling W, et al. (2017) The relationship between iodine intake and the risk of thyroid cancer. Medicine 96(20): e6734-e6738.

2. Albano D, Bertagna F, Bonacina M, Durmo R, Cerudelli E, et al. (2018) Possible delayed diagnosis and treatment of metastatic differentiated thyroid cancer by adopting the 2015 ATA guidelines. European Journal of Endocrinology 179(3): 143-151.

3. Nozha OMA, Vautour L, How J (2011) Life-threatening hyponatremia following a low-iodine diet: A case report and review of all reported cases. Endocrine Practice 17(5): e113-e117.

4. Chi Young L, Jung Yeon K, Mi Jin Y, Hang Seok C, Cheong Soo P, et al. (2015) Effect of a low iodine diet vs. restricted iodine diet on postsurgical preparation for radioiodine ablation therapy in thyroid carcinoma patients. Yonsei Medical Journal 56(4): 1021-1027.

5. Li JH, He ZH, Bansal V, Hennessey JV (2016) Low iodine diet in differentiated thyroid cancer: a review. Clinical Nutrition Research 84(1): 3-12.

6. Jahae K, Sang Geon C, Sae Ryung K, Seong Young K, Dong Hyeok C, et al. (2017) Preparation for radioactive iodine therapy is not a risk factor for the development of hyponatremia in thyroid cancer patients. Medicine 96(5): e6004-e6008.

7. Minkyung L, Yu Kyung L, Tae Joo J, Hang Seok C, Bup Woo K, et al. (2014) Low iodine diet for one week is sufficient for adequate preparation of high dose radioactive iodine ablation therapy of differentiated thyroid cancer patients in iodine-rich areas. Thyroid Radiology and Nuclear Medicine 24(8): 1289-1296.

8. Haldimann M, Alt A, Blanc A, Blondeau K (2005) Iodine content of food groups. Journal of Food Composition and Analysis 18(6): 461-471.

9. Ershow AG, Skeaff SA, Merkel JM, Pehrsson PR (2018) Development of databases on iodine in Foods and Dietary Supplements. Nutrients 10(1): 100.
10. Binh NG, Quynh HT, Huyen NT (2013) Efficiency of Iod Diet in Postsurgical Differentiated Thyroid Cancer Patients before I-131 Treatment. Jounal of 108- Clinical Medicine and Pharmacy 8(6): 134-137.

11. (2011) National Institute of Nutrition and UNICEF. A review of the nutrition situation in Viet Nam 2009-2010. Hanoi: Medical Publising House.

12. Mitchell AL, Gandhi A, Scott Coombes D, Perros P (2016) Management of thyroid cancer: United Kingdom National Mutidisciplinary. The Journal of Laryngology and Otology 130(Suppl 2): S150-S160.

13. Haugen BR, Alexander EK, Bible KC, Doherty GM, Mandel SI, et al. (2016) 2015 American thyroid association management guidelines for adult patients with thyroid nodules and differentiated thyroid cancer: The American Thyroid Association Guidelines Task Force on Thyroid Nodules and Differentiated Thyroid Cancer. Thyroid 26(1): 1-133.

14. Dal Lae J, Young Joo P, Hee Young P, Yoon Ju S (2015) The impact of low adherence to the low-iodine diet on the efficacy of the radioactive iodine ablation therapy. Clinical Nutrition Research 4(4): 267-271.

15. Jeong Ah M, Chang Hee Y, Mi Hwa K, Song Mi L, Young Ja O, et al. (2012) Knowledge, self-efficacy, and perceived barriers on the low-iodine diet among thyroid cancer patients preparing for radioactive iodine therapy. Clinical Nutrition Research 1(1): 13-22.

16. Dal Lae J, Young Joo P, Hee Young P, Min Ji K, Seonyeong P, et al. (2016) Dietary evaluation of a low-iodine diet in Korean thyroid cancer patients preparing for radioactive iodine therapy in an iodine-rich region. Clinical Nutrition Research 10(2): 167-174.

17. Margareta Dobrenic DH, Marijan Zuvic, Darko Grosev, Ratimir Petrovic, Tatjana Samardzic (2011) Usefulness of low iodine diet in managing patients with differentiated thyroid cancer-initial results. Journal of Radiology and Oncology 45(3): 189-195.

18. British Thyroid Association (2018) The low iodine diet. UK Low Iodine Diet working group.

19. Perros P, Boelaert K, Colley S, Evans C, Evans RM, et al. (2014) Radioiodine remnant ablation and therapy for differentiated thyroid cancer, in Guidelines for the management of thyroid cancer. Clinical Endocrinolm, p. 37-47.

20. Chung JH (2013) Low iodine diet for preparation for radioactive iodine therapy in differentiated thyroid carcinoma in Korea. Endocrinology and Metabolism 28(3): 157-163.

21. Ministry of Health and National Institute of Nutrition (2007) Vietnamese Food Composition Table. Medical Publishing House. 


\section{ISSN: 2574-1241}

DOI: 10.26717/BJSTR.2019.17.002939

Nguyen Thu Ha. Biomed J Sci \& Tech Res

(c) (P) This work is licensed under Creative

Submission Link: https://biomedres.us/submit-manuscript.php

$\begin{array}{ll}\text { BIOMEDICAL } & \text { Assets of Publishing with us } \\ \text { RESEARCHES } & \text { - Global archiving of articles } \\ & \text { - Immediate, unrestricted online access } \\ & \text { - Rigorous Peer Review Process } \\ \end{array}$

